\title{
Language and Spatial Frames of Reference in Mind and Brain
}

\author{
C. R. Gallistel \\ Rutgers University ${ }^{1}$
}

Introspectively, language seems so closely connected to the process of thinking as to be indistinguishable from it. Our thoughts seem to spring into existence as the words that express them are formed. This accounts perhaps for the enduring appeal of the thesis that our language determines significant aspects of our thought. In its strongest form, this is the thesis that the concepts that we manipulate in thinking are the concepts provided by our language (Whorf, see Carroll, 1956; for more recent elaborations of views along these lines, see Gumperz \& Levinson, 1996). The intimate association between our language and our introspective experience of thought may also explain the continuing appeal among philosophers of Descartes' argument that animals do not have thoughts (Davidson, 2001; Sellars, 1956/1963). If (human) languages are the media of human thoughts (cf. Quine, 1960), then non-human animals do not have anything like human thoughts. The alternative view is that language is merely the vehicle by which humans communicate concepts that exist prior to and independently of their linguistic encoding. In the latter case, humans speaking radically different languages and animals with no language at all may all entertain the same concepts--and we may hope to have a zoologically unified cognitive science.

In recent years, the Whorfian hypothesis has enjoyed a revival in anthropology, psychology and linguistics, fueled in appreciable measure by studies on cross-cultural correlations between variations in spatial language use and variations in performance on seemingly simple tests of spatial conceptualization (Brown \& Levinson, 2000; Levinson, 1996; Levinson \& Brown, 1994; Pederson et al., 1998). In English, the "south end of a horse headed north" is a humorous locution because it seems to choose an absurdly awkward frame of reference in which to indicate the end of the horse that is meant. Telling someone to look at the tree upslope of them--in lieu of telling them to look at the tree in front of them---strikes most Europeans as a similarly awkward. It uses an allocentric (other centered) frame in a context where an egocentric (subject centered) frame seems called for or natural. However, this locution does not seem bizarre to speakers of languages in which words that require an egocentric frame of reference for their interpretation occur rarely (or, perhaps, not at all). For example, it seems perfectly natural to the approximately 15,000 speakers of the Mayan language Tzeltal, who live in villages ranged along the side of a extensive hill in the Tenejapa region of Chiapas, Mexico. They rarely or never use words that invoke an egocentric frame or reference (Levinson, 1996). Does this mean that their language has made them conceptualize space differently from us? Do they conceptualize it in an allocentric frame, whereas we

\footnotetext{
${ }^{1}$ Rutgers Center for Cognitive Science 152 Frelinghuysen Road

Piscataway, NJ 08854-8020 galliste@ruccs.rutgers.edu
} 
conceptualize it in an egocentric frame? (And, if so, should we feel guilty about our selfcenteredness?)

Pederson, et al. (1998) put this question to an experimental test (the scientific question, not the moral one). They placed three plastic animals nose-to tail on a table top, then asked their subjects to duplicate the arrangement on a second table, while facing in the opposite compass direction. Tzeltal-speaking subjects recreated the allocentric orientation, whereas Dutch-speaking subjects recreated the egocentric orientation (Figure 1A). Pederson, et al. (1998) think that at the very least this suggests that the daily speaking of a language in which uphill/downhill cross-the-hill is the linguistically picked out frame of reference inclines subjects to conceptualize spatial relations in that frame of reference, whereas the speaking of a language in which the egocentric frame is much more often picked out inclines those speakers to conceptualize in that framework. This is the cautious form of the Whorfian thesis. A stronger thesis would be that the egocentric frame of reference does not exist for the Tzeltal-speakers, because words for it do not exist in Tzeltal. It is not always clear which form of this thesis Pederson, et al. (1998) wish to argue for.

But do these results imply such a conclusion? After conducting similar experiments with English-speaking subjects, Li and Gleitman(2002) suggest that they do not. They begin by noting an easily overlooked methodological detail in the Pederson, et al. (1998) experiments: The Tzeltal-speaking subjects were tested outside, on their hillside, whereas the Dutch subjects were tested in rectangular laboratory rooms, with no perceptual access to the larger world. Li and Gleitman show that native English-speaking subjects behave like Dutch-speaking subjects when tested in a room with the blinds down, shutting out the view to the outside, but much more like Tzeltal-speaking subjects when the blinds are raised. They also show that marking one end of the two tables with reference objects of identical appearance makes the English-speaking subjects behave exactly like the Tzeltalspeaking subjects. They arrange the animals on the second table so that they point to (or away from, as the case may be) the marked end of the table, just as they did on the first table. In preserving the orientation relative to the marked end of the two tables, subjects reverse the egocentric orientation of the array. Li and Gleitman point out that similar manipulations change the behaviorally controlling spatial framework in subjects that have no language - infant humans and rats (Acredolo, 1979; Gallistel, 1990, Chap. 6; Restle, 1957). Their results and arguments call for caution in assessing the import of the Pederson, et al. (1998) results.

One question that needs to be asked is what it might mean to say that Tzeltal speakers don't have (or rarely entertain) an egocentric conceptualization of the position of an object. Elementary perceiving and acting seem to require continual coordinate transformations, because the sensory receptor surfaces that pick up directional information and the muscles that implement directed actions operate in physically distinct coordinate frameworks. These different frameworks generally do not even have the same dimensionality (the same number of degrees of freedom), let alone the same axes (Gallistel, 1999). Moreover, they constantly shift relative to one another. For example, at the lowest level of encoding, the direction of a visual stimulus is retinotopically coded, because objects (distal stimuli) in different directions from they eye give rise to images (proximal stimuli) at different locations on the retina. But the position of the proximal 
Figure 1. A. The Pederson, et al. (1998) experiment, extended by Li \& Gleitman (2002).

Subject arranges toy animals on a table, then turns $180^{\circ}$ and replicates the arrangement on a second table. The question is whether the replication preserves the allocentric (compass) orientation of the original or its egocentric orientation. B. The doublesaccade experiment. Inducing the eye to make a saccade that intervenes between the delivery of a flash and a (second) saccade that foveates the source of the flash, provides a simple example of the ubiquitous need for the nervous system to represent positions in multiple coordinate frameworks. Before the intervening saccade, the proximal stimulus strikes the fovea to the left of the retina, indicating that the source of the light (the distal stimulus) is to the right of the optical axis. However, by the time the saccade intended to foveate the source occurs, an intervening movement of the eye has

changed the position of the distal stimulus in the optical (or motor) coordinate system thereby changing the pattern of muscle activation required to foveate it. The superior colliculus computes the coordinate transformation required to map the retinal coordinates of the proximal stimulus together with signals specifying the intervening movement of the eye into a representation of the current position of the distal stimulus in the optical (motor) framework (see Gallistel, 1999 and Sparks \& Mays, 1990 for reviews).

stimulus does not determine the pattern of muscular contraction required to direct the eyes so as to bring the image of the distal stimulus onto the fovea. If the eye moves between the time when the flash strikes the retina and the time when the foveating saccade is initiated, the relation between the sensory framework and the response 
framework changes (Figure 1B). When a flash falls to the left of the fovea, then, to foveate the distal stimulus, the muscles on the right side of the eye must contract and the muscles on the left relax-provided the eye has not moved between the flash and the start of the saccade. If, however, the eye has moved in the interim, then the requisite pattern of muscular contraction may be reversed (Figure 1B). It will, in any event, be different than it would have been had their been no intervening movement. In the superficial layers of the superior colliculus, the brain encodes the proximal stimulus in retinotopic coordinates, whereas in the deep layers of the same structure, it encodes the distal stimulus in optocentric (or motor) coordinates ( see Gallistel, 1999, for review; also Mays \& Sparks, 1980; Sparks \& Mays, 1990).

The relevance of these and similar neurobiological findings is that the nervous system codes the distal positions of objects and the proximal stimuli they give rise to in many different coordinate frameworks. The use of a multiplicity of coordinate frameworks for the representation of spatial relations between the animal and its environment seems almost an analytic necessity. It is hard to see how one could engineer a system for generating directed action without coding position in different frameworks. There is also considerable evidence from psychophysics and systems electrophysiology that the brain routinely does this (e.g., Muller, 1996; Snyder, Grieve, Brotchie, \& Andersen, 1998; Taube, Muller, \& Ranck, 1990). If it is agreed that directed action requires both (various forms of) egocentric and allocentric positional encoding within the brain itself, whether or not that brain can generate or understand a human language, then how do we make intelligible the claim that a human brain lacks altogether, or fails to make routine use of, both egocentric and allocentric representations of position?

\section{References}

Acredolo, L. P. (1979). Laboratory versus home: The effect of environment on the 9month-old infant's choice of spatial reference system. Developmental Psychology, 15(6), 666-667.

Brown, P., \& Levinson, S. C. (2000). Frames of spatial reference and their acquisition in Tenejapan Tzeltal. In L. Nuccie \& G. Saxe \& E. Turiel (Eds.), Culture, thought and development (pp. 167-197). Mahwah, NJ: Erlbaum.

Carroll, J. B. (Ed.). (1956). Language, thought and reality: Selected writings of Benjamin Lee Whorf. Cambridge, MA: MIT Press.

Davidson, D. (2001). Subjective, intersubjective, objective. Oxford: Oxford University Press.

Gallistel, C. R. (1990). The organization of learning. Cambridge, MA: Bradford Books/MIT Press.

Gallistel, C. R. (1999). Coordinate transformations in the genesis of directed action. In B. O. M. Bly \& D. E. Rummelhart (Eds.), Cognitive science (pp. 1-42). New York: Academic.

Gumperz, J. J., \& Levinson, S. C. (Eds.). (1996). Rethinking linguistic relativity: Studies in the social and cultural foundations of language. No. 17. Cambridge: Cambridge University Press.

Levinson, S. C. (1996). Frames of reference and Molyneux's question: Cross-linguistic evidence. In P. Bloom \& M. Peterson \& L. Nadel \& M. Garrett (Eds.), Language and space (pp. Chap. 4). Cambridge, MA: MIT Press. 
Levinson, S. C., \& Brown, P. (1994). Immanuel Kant among the Tenejapans: Anthropology as empirical philosophy. Ethos, 22(1), 3-41.

Li, P. W., \& Gleitman, L. R. (2002). Turning the tables: language and spatial reasoning. Cognition, 83(3), 265-294.

Mays, L. E., \& Sparks, D. L. (1980). Dissociation of visual and saccade-related responses in superior colliculus neurons. J. Neurophysiol., 43, 207-232.

Muller, R. U. (1996). A quarter of a century of place cells. Neuron, 17, 813-822.

Pederson, E., Danziger, E., Wilkins, D., Levinson, S. C., Kita, S., \& Senft, G. (1998). Semantic typology and spatial conceptualization. Language, 74(3), 557-589.

Quine, W. V. (1960). Word and object. Cambridge, MA: MIT Press.

Restle, F. (1957). Discrimination of cues in mazes: A resolution of the place-vs.-response question. Psychological Review, 64, 217-228.

Sellars, W. (1956/1963). Empiricism and the Philosophy of Mind. In P. Kegan (Ed.), Science, perception and reality. London: Routledge.

Snyder, L. H., Grieve, K. L., Brotchie, P., \& Andersen, R. A. (1998). Separate body- and world-referenced representations of visual space in parietal cortex. Nature, 394, 887891.

Sparks, D., \& Mays, L. E. (1990). Signal transformations required for the generation of saccadic eye movements. Ann. Rev. Neurosci., 13, 309-336.

Taube, J. S., Muller, R. U., \& Ranck, J. B. (1990). Head-direction cells recorded from the postsubiculum in freely moving rats. I. Description and quantitative analysis. J. Neurosci., 10(2), 420-435. 